\title{
Investing Well by Investing for Good?: Exploring the Motivations of Socially Responsible Investors*
}

\author{
HANNAH JUN ${ }^{* *}$
}

Investments in socially responsible investing (SRI), an investment process that integrates environmental, social, and governance considerations into investment decisionmaking, have grown rapidly in many areas around the world. But compared to the growth of SRI investments on a global level, there is little clarity in the academic literature about why investors would choose to implement such a strategy. This paper attempts to highlight key theories and approaches to understand the motivetions of socially responsible investors and, in doing so, provide a more robust theoretical framework that underpins the recent global phenomenon.

Keywords: Socially Responsible Investing, SRI, Investor Behavior, Corporate Social Responsibility

** The work was supported by the Ewha Global Top 5 Grant 2011 of Ewha Womans University.

** Lecturer, Hanyang University; E-mail: jun.hannah@gmail.com 


\section{INTRODUCTION}

Investments in socially responsible investing (SRI), an investment process that integrates environmental, social, and governance considerations into investment decision-making, have grown rapidly in many areas around the world. Recent data suggests that in the United States alone, one out of every eight dollars under professional management (or 12\% of US \$25 trillion in total assets under management) is involved in socially responsible investing (US SIF 2010). In Europe, total SRI assets under management increased from $€ 2.7$ trillion in 2007 to $€ 5$ trillion in 2009 , representing growth of about $87 \%$ over the two-year period (Eurosif 2010).

On the one hand, there is little debate about what constitutes SRI. Most definitions allude to considerations of environmental, social, and governance (ESG) issues in investment decision-making, and point to a variety of strategies and methods to achieve this goal. For example, the US SIF defines SRI as "a broad-based approach to investing that $\cdots$ considers both the investor's financial needs and an investment's impact on society. SRI investors encourage corporations to improve their practices on environmental, social, and governance issues." Similarly, Eurosif defines SRI as "investing that is mindful of the impact those investments have on society. SRI traditionally combines investors' financial objectives with their concerns about environmental, social and governance (ESG) issues."

But while there is greater consensus on the definition of SRI, there is less understanding in the academic literature about why investors would choose to implement such a strategy. This is further complicated by the observation that SRI is often shaped by a range of actors and a variety of motivations. For example, while Michelson et al. (2004) place primary importance on the relationship between investors and firms in investment decision-making, scholars such as Williams (2007) highlight the potential role of external factors such as market context, institutional ownership, and the regulatory environment in shaping investment preferences and behavior.

To better understand the motivations underlying and actors driving the SRI market, this paper classifies and highlights key theoretical approaches to provide a more robust framework from which to understand the global SRI 
growth phenomenon. As a starting point, this paper adopts an institutional approach to examine what institutional factors prompt investors (and firms) to engage in socially responsible behavior (e.g., Aguilera et al. 2007; Matten and Moon 2008). Regarding corporate social responsibility (CSR) and the firm, Aguilera et al. (2007) identify instrumental, relational, and ethical motivations in building a theoretical framework to understand why and at what levels firms adopt socially responsible behavior. This paper extends the classification and organizes relevant literature on the motivations for and incentives underpinning SRI as follows:

1. Instrumental theories: A group of theories and approaches in which SRI serves as an instrument for wealth creation. This group emphasizes the economic aspect of SRI in that SRI is acceptable if it is consistent with wealth creation. According to Aguilera et al. (2007), instrumental motivation is driven purely by self-interest at the firm level (or investing body, in the case of SRI) and is associated with enhancing leading firms' international competitiveness at the national level, thus placing emphasis on the competitive aspect.

2. Relational theories: A group of theories in which SRI reflects the integration of social demands. This group argues that the relational motivation is driven by the need to maintain cooperative relationships among stakeholders and is associated with minimizing social exclusion and building social cohesiveness.

3. Ethical theories: A group of theories which understands that the relationship between business and society is embedded with ethical values. The motivations for SRI extend from an ethical perspective and have their roots in moral or ethical principles stemming from the individual, firm, and national levels. This group acknowledges the role of long-standing and deeply-embedded national values as well as collective responsibility for social progress, which may include economic development.

As noted by Kang and Moon (2012), the three motivations are not mutually exclusive, but rather they co-exist to varying degrees in different contexts and help identify the institutional antecedents of CSR motivations that 
are not easily articulated in the rhetoric. With this in mind, this paper expands on this classification by examining key literature in the field.

\section{INSTRUMENTAL THEORIES}

Instrumental theories and approaches address SRI as an instrument for wealth creation. To some extent, the definition of SRI necessarily includes the goal of achieving satisfactory returns on investment. But depending on the theoretical approach and, specifically, the goals of the national business system, there are meaningful differences in the priorities and modes of wealth creation.

\section{Maximization of Shareholder Value}

Given that SRI is defined in part by generating reasonable returns on investment, a substantial group of literature is devoted to evaluating SRI performance to examine whether or not SRI makes investment sense. Certain approaches regarding the maximization of shareholder value posit that profitseeking behavior does not necessarily exclude taking into account the interests of those who have a stake in the firm. Indeed, it has been argued that under certain conditions, the satisfaction of these interests can contribute to maximizing shareholder value (e.g., Mitchell et al. 1997; Ogden and Watson 1999). From an investment perspective, this view can support several investment rationales. First, more socially-responsible firms may prove to be more profitable in the longer term due to efficient resource usage, greater acceptance by a range of stakeholders, better accountability, and good governance. In addition, the rise of the conscious (ethical) consumer may constitute a growing market for "good" firms and subsequently increase market opportunities for socially responsible firms (e.g., Vogel 2005).

To explore whether empirical evidence to date supports these theoretical propositions, many studies have attempted to measure the performance of "good" firms as well as funds investing in them. Regarding the former, a large group of literature aims to explore the link between corporate social responsibility and financial performance. Barnett and Salomon (2006) empirically 
test whether SRI funds with weak screening standards are more diversified and achieve improved risk-adjusted returns vis-à-vis SRI funds with more stringent screening standards. Results suggest that the relationship between social responsibility and financial performance is indeed curvilinear for the 61 funds in the analysis. In addition, the study examines whether financial performance varies depending on the type of social screen applied. Findings suggest that community relations screening increased performance, while labor relations and environmental performance screening decreased performance. In this sense, the study cautiously suggests that the financial costs of increasing equal employment/diversity and environmental performance in-line with rigid screening standards of some SRI funds may outweigh their financial benefit.

Conversely, several studies suggest that there is a positive relationship between corporate social responsibility and financial performance. Van de Velde et al. (2005) suggest a positive relationship between stock returns and sustainability ratings based on four constructed sustainability groups: (1) best; (2) good; (3) bad; and (4) worst. The findings on the study of stocks in the Eurozone between 2000 and 2003 support those of Derwall et al. (2005), but contrast findings by Brammer et al. (2006) which focused on "ethical" rather than sustainability criteria.

In addition to exploring the link between CSR and firm performance, a growing group of literature has focused on SRI fund performance versus that of conventional indices. For example, Schröder (2004) tests the performance of SRI funds and indices versus conventional assets in the United States, Germany, and Switzerland, as measured by Jensen's alpha. Results suggest that the majority of SRI indices exhibit performance that is similar to or slightly better that of conventional benchmark indices between the mid-1990s to September 2002. In addition, a study by Statman (2000) compares returns between the Domini Social Index (DSI) with the S\&P 500 in the United States between May 1990 and September 1998 while also examining performance of 31 socially responsible mutual funds over the same period. The study suggests that the DSI performed as well as the S\&P 500, supporting the hypothesis that pooling investing power for something other than making money (i.e., combining social goals with investments) is no worse at making money than pooling investing power for the purpose of making money alone. In addition, 
findings also support the hypothesis that returns for socially responsible mutual funds do not fall short of those for conventional funds.

A further study by Statman (2006) extends the data and examines whether returns of socially responsible stocks are likely to be higher or lower than those of conventional stocks and what the tracking errors of socially responsible stock portfolios are relative to conventional benchmarks. Results suggest that returns of socially responsible indexes generally exceeded returns of the S\&P 500 index over the period of the study and that while the correlation between returns of socially responsible indexes and the S\&P are high, tracking errors may be substantial.

Other studies, however, do not suggest as positive a relationship between SRI fund performance and that of conventional indices. For example, Bello (2005) examines performance of SRI funds relative to conventional mutual funds and also sets out to empirically test the association between social screening and characteristics of companies in the portfolio, including diversification and size. The broad study looks at 42 SRI funds and 84 conventional funds in the United States between January 1994 and March 2001, and finds that "not a single characteristic of socially responsible mutual funds is significantly different from that of conventional funds" (2005, 50). Specifically, findings suggest that screening does not introduce a significant size bias and risk-adjusted performance of SRI and mutual funds are not significantly different.

As indicated in the review of literature, results on financial performance have largely been mixed, although with a slight positive bias. Considering the literature to date, key reasons for mixed results may include differences regarding one or more of the following factors: (1) definition of socially responsible behavior (or target outcome of SRI investors); (2) research methodology, particularly data source and time period of analysis; and (3) variations given geographic region. Already in the CSR literature, several scholars have called for a temporary ceasefire in the examination of CSR and financial performance so that, at the very least, scholars may have room to focus on other theoretical approaches and issues related to CSR (e.g., Margolis et al. 2007; Wood 2010). With socially responsible investing, however, the need to analyze returns on investment will likely remain a critical aspect of evaluating SRI as a viable 
investment strategy going forward. This need has undoubtedly spurred the numerous empirical studies on SRI and wealth creation as consistent with the goal of maximizing shareholder value.

But while the demand for empirical analyses will continue going forward, both the example from CSR literature and results of SRI empirical studies to date suggest that there are other issues that need to be considered in the examination of SRI's dual goals of achieving financial success and bringing about desirable social outcomes. In addition, while the purely economic element of the SRI model cannot be entirely ignored, it is difficult to conclude from existing literature that SRI is used solely as a tool for wealth creation. In fact, scholars such as Williams (2007) argue that "SRI provides prima facie evidence that financial returns may not be the only criteria used by a significant number of investors, and that ethical and social considerations may also play an important role" (43). This has prompted scholars to explore investor behavior and potential trade-offs in investing in SRI, in particular the possibility that investors derive non-financial utility from the SRI process (e.g., Renneboog et al. 2008).

While the type of non-financial utility desired may depend on unique goals of the investing body or preferences of individual investor, a growing body of literature explores the role of institutional features in shaping the idea of "desirable" firm behavior and articulating the desired role of firms in society. With regards to SRI literature, an understanding of the national business system and how it shapes goals and expectations may shed light on what institutions, mechanisms, and incentives influence investor sentiment and ultimate behavior.

\section{National Business Systems and Institutional Complimentarity}

In addition to exploring shareholder value maximization as a primary motivation for SRI, a growing body of literature has focused on the role of the national business system in influencing and shaping motivations and outcomes for corporate social responsibility. On the one hand, the definition of "socially responsible" or "desirable" behavior is often shaped by social agendas driven by local culture, expectations, and priorities. For example, in response to 
Carroll's (1991) pyramid of corporate social responsibilities, Visser (2006) challenges the model's relevance in the developing world as the relative priorities of CSR-which form in response to, among other things, dynamics of the national business system-are arguably different from those of the classic, American ordering. Blowfield and Frynas (2005) also argue that issues such as stakeholder engagement present particular challenges in developing countries where factors such as language, culture, education, and pluralistic values may affect the process of negotiation and decision-making. They also question whether corporations, built on a western economic model, can recognize values rooted in other cultures. Given these observations, many studies have explored the meaning and practice of CSR within a range of geographic contexts.

Along this vein, there have been several studies focusing on the national business system. This view contends that behavior and performance of firms (and by extension, investing bodies) often depends on national institutional arrangements that govern finance and labor, and if these arrangements are coordinated in a complimentary manner, they accord a "competitive institutional advantage" to firms (e.g., Amable 2003; Hall and Soskice 2001; Kang and Moon 2012; Yamamura and Streeck 2003). In addition, recent work on comparative institutional research regarding corporate social responsibility has explored links to broader literature on comparative capitalism (e.g., Matten and Moon 2008; Gjølberg 2010; Jackson and Apostolakou 2010). Notably, Matten and Moon (2008) attribute the difference between "explicit" CSR in the United States and "implied" CSR in Europe to nationally distinct business systems, where concentrated financial systems, regulated education and labor systems, and cultural systems skeptical of business and confident about government have shaped an embedded culture of CSR in European economies. These findings were echoed by Gjølberg (2010), who attributed "institutions for social embedding," such as an extensive welfare state, strong neocorporatist arrangements, and a culture of political participation, to Europe's commitment to CSR.

From this perspective, an understanding of the modes of capitalism can help reveal the institutional mechanisms and expectations underpinning the conceptualization of socially responsible behavior. Fundamentally, this exploration of national business systems focuses on static, comparative aspects 
across countries and suggests that distinctive national business systems arise from differences in economic organization at the national level (e.g., Moskalev and Park 2010; Xu and Yang 2010; Jamali and Mirshak 2007). For example, Haake (2002) analyzes individualistic business systems versus communitarian business systems to understand how national models of capitalism link to industry-specific national competitive advantage, citing the cases of the United States, Japan, Germany and Britain. In addition, Chapple and Moon (2005) find that while national levels of CSR are enhanced by international exposure, this does not necessarily mean that multinational corporations (MNCs) impose a profile of CSR on their host countries. Rather, the study finds that MNCs appear to conform to the respective national profiles. In this sense, differences in national business systems can help to explain divergences in generally accepted socially responsible behavior and merits academic attention.

In categorizing modes of capitalism, Hall and Soskice (2001) distinguish two types of capitalism: (1) liberal market economies (LMEs); and (2) coordinated market economies (CMEs). According to the categorization, LMEs are characterized as exhibiting relations between firms and other actors coordinated primarily by competitive markets, with primary examples including the United States and United Kingdom. In CMEs, such as Germany or Japan, firms typically engage in more strategic interaction with trade unions, suppliers of finance, and other actors. As an extension, Kang and Moon (2012) suggest the inclusion of state-led market economies (SLME), where the state plays the dominant role, in the analysis. They suggest that economies such as France and South Korea would fall under this categorization.

This strand of literature on national business systems and institutional complimentarity argue that the concept and practice of socially responsible behavior depend in large part on the institutional arrangements underpinning the economic system. Specifically, scholars such as Kang and Moon (2012) recognize that CSR assumes both voluntary and non-voluntary forms and fulfills different functions (competitive, socially cohesive, and developmental) in different contexts and at different times. As such, one of the strengths of this approach is that it goes beyond rhetoric and enables an analysis of specific institutions and mechanisms, as well as different types and functions of socially responsible behavior, making it even more useful in undertaking comparative studies of CSR and SRI. 


\section{RELATIONAL THEORIES}

In investigating what institutional factors prompt investors (and firms) to engage in socially responsible behavior, relational theories examine how social demands are integrated in corporate decision-making, firm operations, as well as investment. This group generally argues that business relies on society for its existence, continuity, and growth, and that the integration of social values and demands serves as the basis for the firm's legitimate functioning in society. This view highlights several implications to SRI. From an economic perspective, if society grants legitimacy to (i.e., rewards) firms that function in-line with the interests of various groups, it makes sense for investors to invest in firms that successfully integrate social demands. From the perspective of SRI's goal of achieving specific social aims, investing in firms that successfully integrate social demands favored by SRI institutions is consistent with the basic tenets of SRI. In fact, the existence of social demands for particular issues (e.g., environmental protection) or industries has been shown to directly lead to the establishment of SRI funds or institutions, thus serving as a theoretical foundation for investment strategies such as thematic investment.

Relational theories in CSR literature have focused on specific actors affected by the operations of a firm. For example, literature suggests that firms may engage in socially responsible behavior due to pressure from stakeholders, such as investors (Mackey et al. 2007), NGOs, governments (Donaldson and Preston 1995), consumers (McWilliams and Siegel 2001; Schuler and Cording 2006), employees, and the greater community (Aguilera et al. 2007; Barnett 2007; Baron 2001). In reviewing relevant literature from the perspective of SRI, this paper presents a critical review based on the desired SRI outcome, namely: (1) environment; (2) social; and (3) governance. This categorization may help to shed light on how SRI funds rationalize the incorporation of some or all ESG issues in their investment strategy.

\section{Environmental Perspective}

The wealth of literature regarding the impact of business on the environment may reflect the visible damage to natural resources, biodiversity, and 
concerns on global warming that have grown largely alongside the rise of multinational corporations (MNCs). As a result, there has been a rich history of action by individual activists and NGOs, national governments, as well as international bodies such as the United Nations in addressing larger issues of resource usage and sustainability-particularly with implications to corporate practices. One primary reason for targeting corporations is that, by virtue of their size and business scope, their impact to the environment has been most evident and far-reaching. Recent incidents such as BP's Deepwater Horizon oil spill highlight this point clearly.

In the academic literature, one rationale for large corporations to move large-scale operations overseas has included access to cheap labor and lower costs due to less stringent monitoring of business practices, including environmental regulations. In other words, as noted by Dasgupta et al. (2001), some studies suggest that firms in developing countries do not have incentives to invest in pollution control due to weak implementation of environmental regulations (e.g., O'Connor 1995). As a result, scholars may assume that the costs of compliance exceed expected benefits and that environmental regulators are the only agents that can penalize firms lacking pollution control efforts (Dasgupta et al. 2001).

However, other studies examining the impact of environmental regulations on international competitiveness suggest that pollution-intensive firms have not relocated in developing countries to benefit from lower environmental standards and or poor enforcement of environmental regulations. For example, Hettige et al. (1992) observe that "one possibility is that the expected profitability of investment in pollution-intensive sectors has also been affected by growing concern over legal liability or reputational damage" (480). Along this vein, findings by Dasgupta et al. (2001) suggest that at least in the specific cases of publicly-traded companies, specifically for those in Argentina, Chile, Mexico, and the Philippines, the assumed benefits of traditionally poor enforcement of environmental compliance may have been "significantly overestimated" (312).

On the one hand, corporate use and misuse of the environment has contributed to the strengthening of legal regulations and international codes of conduct regarding the impact of firms on the environment. But contrary to the 
view that a lack of compliance to environmental regulations constitutes an economic benefit to the firm, reckless behavior may result in real costs to the firm due to potentially negative impacts to employees (e.g., health, morale), clean-up costs in the event of major accidents, the issue of resource consumption and sustainability, and loss of trust from consumers, the local government, as well as the investing community. As such, scholars such as Henriques and Sadorsky (1999) highlight that managerial perception of stakeholder importance and standards of ethical behavior play a role in shaping environmental commitment at the firm level.

Regarding the link between firm commitment to the environment and SRI, recent literature also explores whether such commitment results in a cost to socially responsible firms. In an evaluation of high-ranked equity portfolios versus low-ranked counterparts, Derwall et al. (2005) find that between 1995 and 2003, the more socially responsible (high-ranked) portfolio exhibited substantially higher returns that could not be explained by differences in market sensitivity, investment style, or industry-specific factors. The study adds to the work on "eco-efficiency," or the economic value of that a firm can create relative to the waste it generates, by suggesting that SRI produces superior returns.

On the one hand, studies supporting the view that investment in socially responsible firms (particularly with regards to environment stewardship) can generate higher returns for socially responsible investors add credence to the ability of the SRI investment model to generate both reasonable financial returns and fulfill a specific social outcome. Additionally, from the perspective of investors, attractive features of analyzing corporate environmental performance in investment decision-making include the measurability and growing disclosure of such data, reflective of both regulatory considerations and firm commitment. Such data may make it easier for funds to gauge and track corporate environmental performance for inclusion or exclusion in portfolios.

\section{Social Perspective}

While the types and measures of issues covered under the environmental perspective are generally well-defined, the social perspective is characterized 
as a broader and patchier arena. For example, the US SIF categorizes social screens used in SRI as dealing with issues of: (1) community development; (2) diversity and equal employment opportunities; (3) human rights; and (4) labor relations. Depending on the social screen, this can also be broadened to include issues such as supply chain management (SCM) and fair trade.

On the one hand, scholars such as Hillman and Keim (2001) suggest that the expansion of responsibilities for business is intuitively appealing to those who view governments as unable or unwilling to deal with such problems. This view is reflected by studies in the CSR literature that suggest that institutional gaps may contribute to greater expectations for resource-rich firms to engage in a wider range of activities not necessarily related to their core economic function (e.g., Visser 2006, 2008).

For those of the traditional shareholder-centric view of the firm, this may serve as a stumbling block as shareholder resources are used for purposes that may not necessarily serve to increase shareholder value. Largely in response to such concerns on the economic impact to firms in engaging in broader social issues, a growing body of literature explores the impact of social issue participation on financial performance. Examples include the study by Hillman and Keim (2001), which test the impact of stakeholder management and social issue participation on financial performance. According to Hillman and Keim (2001), literature regarding the former suggests that building relations with primary stakeholders such as employees, customers, suppliers, and communities could increase shareholder wealth as firms may be able to develop intangible, valuable assets that can be sources of competitive advantage (e.g., Atkinson, Waterhouse and Wells 1997; Barney 1991; Teece 1998), while using corporate resources for social issues not related to primary stakeholders may not create value for shareholders. The propositions were tested with data from S\&P 500 firms and suggest that while stakeholder management leads to improved shareholder value, social issue participation is negatively associated with shareholder value.

But while there may be greater contention in the literature between social outcomes and financial performance, there seems to exist significant anecdotal evidence of managers feeling the need to uphold at least minimum levels of social performance with regards to labor and workplace standards while also 
showing a general commitment to investment in the local community and global issues such as fair trade. This includes the disclosure of fair trade practices among global coffee makers such as Starbucks, more stringent monitoring of contractors for global textile and sports equipment makers such as Gap and Nike, and the widespread adoption of corporate codes of conduct regarding labor standards, equal opportunity, and diversity.

\section{Governance Perspective}

As noted by Kim and Kim (2007), how a firm is governed results from the various implicit and explicit contracts among stakeholders of a firm and the effectiveness with which they are enforced. The idea that the long-term survival of the corporation rests on maximizing the present value of present and future cash flows, and because shareholders constitute residual claimholders with regards to the firm's cash flow, measuring the degree to which a firm focuses on shareholder value maximization has been the primary metric to judge the quality of corporate governance (e.g., Kim and Kim 2007).

To date, the academic and practical implications of corporate governance on firm value has spurred extensive research in this area (e.g., Bauer et al. 2004; Bebchuk and Cohen 2004; Cremers and Nair 2005; La Porta et al. 1998, 2000; La Porta et al. 1999; Shleifer and Vishny 1997). This research includes the evaluation of corporate governance and firm value from a CSR perspective. For example, Gompers et al. (2003) construct a "Governance Index" based on 24 governance rules as a proxy for the level of shareholder rights for roughly 1,500 large firms during the 1990s. Results suggest that firms with stronger shareholder rights had higher firm value, profits, and sales growth while exhibiting lower capital expenditures and fewer corporate acquisitions vis-àvis those with lower shareholder rights.

While there is strong evidence in favor of good corporate governance, such as strengthening independence and oversight capabilities of boards of directors as well as reducing agency costs, moral hazard, and other conflicts of interest, the issue of reinforcing certain corporate governance mechanisms (particularly through regulation) remains contentious. At one level, agency theory suggests that if governance issues need to be addressed, it should be 
dealt with by shareholders rather than government. In addition, the tradition of US-style shareholder capitalism emphasizes the self-regulatory mechanisms of the market and avoids state interference at all costs (save those instances when excessive corporate freedom results in massive economic turmoil).

With regards to the first point, theoretical and anecdotal evidence points to the possibility that shareholders may be unable to tackle governance issues particularly in situations when managers are effectively owners of the firm (e.g., Kim and Kim 2007). In extreme cases, there may be no means for shareholders to monitor managers and ensure that firms are faithfully carrying out their fiduciary duty. With regards to the second point, while the absence of intervention may be desirable for those of the US-style tradition, other economies (particularly developing economies) may benefit from stronger corporate governance regulation if they experience governance gaps due to the incapability or unwillingness of the state (e.g., Visser 2006, 2008). In terms of serving as conduits of change in corporate governance and potentially filling governance gaps, this phenomenon may have significant implications for socially responsible investors.

\section{ETHICAL THEORIES}

According to Smit and Cronje (1997), ethics essentially concerns itself with what is good and right in human interaction. Further broken down, ethics can refer to the set of moral principles or values that drive human behavior (Stevenson 2005). Ethical theories, then, understand that the relationship between business and society is embedded with ethical values. This principle can also be extended to principles guiding investment decisions and strategies. This section reviews motivations for SRI which extend from an ethical perspective and have their roots in moral or ethical principles, including embedded values at the national and international levels.

Carroll and Bucholtz (2000) highlight at least five groups of values that influence managers, including: (1) religious convictions; (2) philosophical views; (3) culture; (4) legal considerations; and (5) professional values. This is in part echoed by Lantos (2002), who suggests that the conscience and critical reasoning ability of individuals also form a means of shaping ethical judgment. 
This section explores in detail religious convictions, culture, and legal considerations.

\section{Religious Convictions}

Early origins of SRI include the influence of religious tradition and values. There exist numerous faith-based SRI funds having roots in JudeoChristian, Catholic, as well as Islamic traditions. Several funds practice investment principles they espouse to be in-line with their faith. For example, MMA Praxis Mutual Funds in the United States emphasizes "stewardship investing" which encompasses social and financial considerations formed through the Christian faith.

Similarly, Ava Maria Funds and LKCM Aquinas Funds represent families of mutual funds that invest according to guidelines set forth by the Catholic Church. In the case of LKCM Aquinas Funds, this includes screening for companies engaged in abortion, embryonic stem cell research, and weapons of mass destruction, as well as companies that maintain poor environmental, human rights, and employment records.

Faith-based funds such as Amana Mutual Funds Trust incorporate Islamic principles in investment strategy. As a result, Amana Mutual Funds Trust utilizes screens for companies who engage in processing pork, alcohol production, or involvement in gambling and insurance. In sum, these examples highlight that the investment criteria and operating principles of some funds are often influenced by religious conviction-particularly in economies where some of the major world religions are practiced.

\section{Culture}

There already exists a substantial group of literature which investigates the role of culture and the concept and practice of corporate social responsibility (CSR). Specifically, while a growing body of research has examined the potential convergence of CSR as international standardization and reporting may reflect a broad alignment of core issues and values with regards to CSR (e.g., Chen and Bouvain 2009; Misani 2010), many scholars (e.g., Jamali 
and Mirshak 2007; Visser 2006, 2008) still note that social agendas are still largely driven by local culture, expectations, and priorities and thus demand further study. If this is the case, local culture and expectations of socially responsible behavior may help highlight the needs as well as opportunities available for socially responsible investors. In this way, local culture and values may have a meaningful impact on the investment objectives and profile of SRI funds in the local context.

Figure 1. CARroll vs. Visser: Pyramid of Corporate Social ResPonsibilities

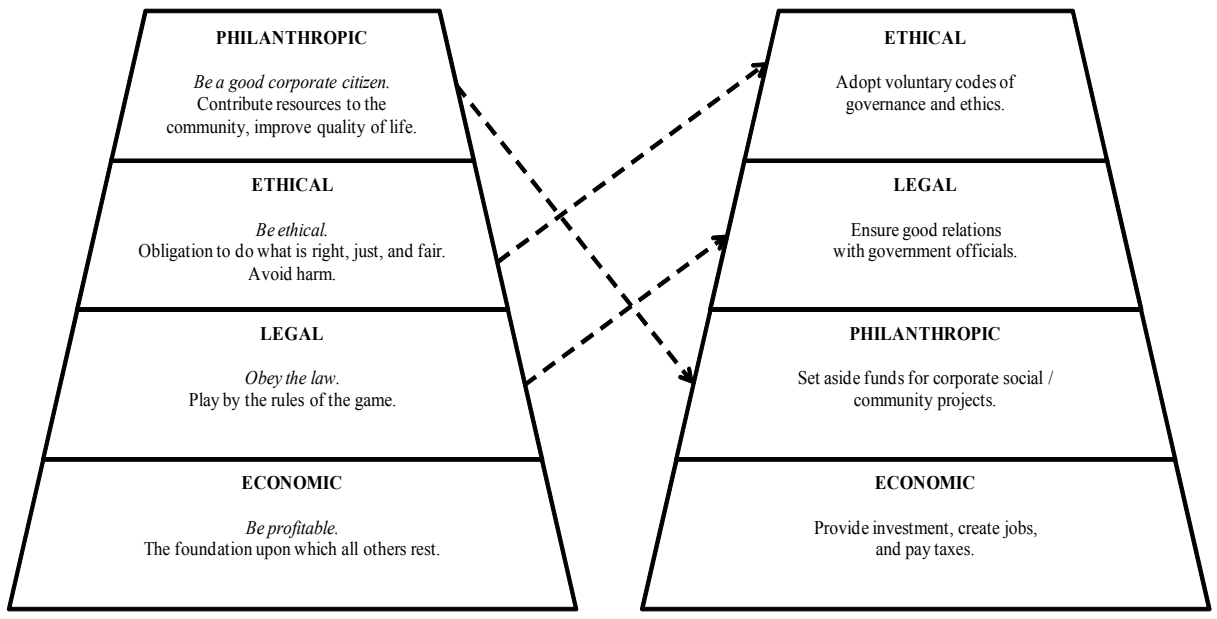

NOTE: Carroll's (1991) pyramid on the left represents the typical, American-based ordering while Visser's (2006) pyramid on the right takes into consideration gaps in governance and cultural tradition, resulting in the relative importance of philanthropic (or discretionary) responsebilities versus legal and ethical ones in many developing countries.

SOURCE: adapted from Carroll (1991) and Visser (2006).

One prominent example of the impact of local culture in shaping concepts of socially response behavior is the comparison between Carroll's (1991) pyramid of corporate social responsibilities versus that of Visser (2006). The former suggests that corporate social responsibilities include economic, legal, ethical, and discretionary ones-in that order. Visser (2006), while acknowledging that the ordering may accurately reflect the priorities of business in an advanced economy such as the United States, suggests that the model is less relevant in explaining the realities of CSR in the developing world. Using the example of African economies, Visser (2006) argues that prominent differences in culture, such as the long-standing tradition of corporate philanthropy, 
along with deficiencies (or gaps) in the rule of law and a history of receiving financial aid that make discretionary considerations much more important to firms. In this sense, firms that understand and respond to such cultural expectations may be able to witness business growth and a greater acceptance by society at large. By extension, SRI funds that can identify such firms for inclusion in portfolios may have the ability to generate reasonable financial returns while also potentially satisfying the social requirement of their investment.

\section{Legal Considerations}

Much literature on CSR has emphasized the rule of law and its role in defining ethical behavior. At the same time, scholars such as Carroll (1991) and those who refer to Carroll's analysis of the pyramid of social responsebilities make a clear distinction between the legal and ethical realms of behavior. An analysis of the classification and commentary by Carroll and Bucholtz (2000) reveals that scholars generally believe that ethical behavior exists at a level above the rule of law. This may be because while the law requires strict compliance, there are no "hard" requirements for compliance to higher standards of ethical behavior.

At the same time, recent movements suggest that the legal climate at the national level impacts corporate behavior and also heightens perceptions of ethical demands by various stakeholders, particularly the government. A recent example of legal considerations contributing to a stronger commitment to ethical behavior is the Sarbanes-Oxley Act (SOX) enacted in the United States in 2002. The Act was promulgated upon the wake of major corporate and accountting scandals, including those involving Enron, Tyco International, Adelphia, Peregrine Systems, and WorldCom, which collectively cost investors billions of dollars and shook public confidence in the securities markets. The Act includes new and enhanced standards for all US public company boards, management, and public accounting firms. Specifically with regards to ethical behavior, Section 406 requires companies to disclose a written code of ethics adopted by the Chief Executive Officer (CEO), Chief Financial Officer (CFO), and chief accountant. 
In addition to broader financial regulations, literature suggests the importance of legal considerations in contributing to a climate of heightened ethical behavior with regards to the environment. For example, Christmann (2004) analyzes the determinants of global standardization of multinational corporations' (MNCs) environmental policies and finds that MNCs standardize different environmental policy dimensions in response to pressures from different external stakeholders. Importantly, Christmann (2004) argues that environmental policy standardization reduces MNCs' ability to exploit cross-country differences in environmental regulations and thus have important implications regarding the self-regulation of MNCs' environmental conduct.

Under the umbrella of governance at the global level, both the number and breadth of international statutes, codes, and guidelines has prompted local governments to strengthen the legal climate at home. This can be demonstrated by state signatories of global environmental initiatives bearing the responsebility of reflecting those provisions through national regulation and/or incentives. These top-down movements may suggest the importance of global agreements and pressure in shaping and reinforcing higher levels of ethical standards in the local context.

\section{RECENT ATTEMPTS AT COMBINING THEORETICAL APPROACHES}

Collectively, the three theoretical approaches aim to explain the motivations and mechanisms shaping SRI investment strategy and preferences. Recent studies have taken this further by attempting to explain to what extent specific factors affect investment decisions by SRI investors. For example, Williams (2007) draws on data from a large survey of investors from Australia, Canada, Germany, the United Kingdom, and the United States to create a general model of investor choice by analyzing potential determinants of the SRI investment choice behavior. These determinants include income levels, gender, education, age, and religion.

Findings suggest that social and environmental behavior on the part of firms is important to investors when making investment decisions, although financial returns and demographic characteristics do not have as much explanatory power in explaining SRI choices. In addition, Williams (2007) notes 
that there was some indirect evidence suggesting that market context, institutional ownership, and regulatory conditions may also shape investment decisions.

Although the study contributes to further understanding individual investor preferences and behavior in Western economies, the model of investor behavior does less to contribute to understanding the role of institutional factors in the decision-making process (other than acknowledging that such factors may shape investor behavior). To help understand these intricacies, further attempts to combine earlier theoretical approaches include a study by Sakuma and Louche (2008) regarding the SRI model in Japan.

In the analysis of Japan's SRI model, Sakuma and Louche (2008) examine the roles and motivations of four specific institutions, namely: (1) SRI research organizations; (2) the Japanese Social Investment Forum (SIF); (3) SRI funds and financial institutions; and (4) firms. The authors argue that an analysis of these institutional features is central to understanding the mechanisms and incentive systems driving the SRI model. The study finds that although Japan has imported a global concept (i.e., SRI), Japan has adapted it to its national context and exhibits several unique characteristics. Specifically, findings suggest that: (1) the relationship between SRI ratings and asset management companies may have contributed to the mainstreaming of SRI; and (2) local grassroots movement among local cooperatives and NGOs may have laid the foundation for the modern-day SRI movement (438).

\section{CONCLUSION}

In light of the rapid growth of SRI investments, this paper attempted to address why investors would implement such a strategy by highlighting key theoretical approaches. After adopting an institutional approach to examine what institutional factors prompt investors and firms to engage in socially responsible behavior (e.g., Aguilera et al. 2007; Matten and Moon 2008), this paper identified instrumental, relational, and ethical motivations for and incentives underpinning SRI. As noted by Kang and Moon (2012), the three motivations are not mutually exclusive, but co-exist to varying degrees in different contexts and help identify the institutional antecedents of socially 
responsible motivations not easily articulated in the rhetoric.

First, instrumental theories highlighted the theories and approaches in which SRI serves as an instrument for wealth creation. This group emphasized the economic aspect of SRI in that SRI is acceptable if it is consistent with wealth creation. Within this group, instrumental theories focused on the motivation of shareholder value maximization in investing in socially responsible firms. Literature in this area argued that socially responsible firms may be able to realize cost reductions, new products, or other efficiencies stemming from socially responsible behavior that may result in greater financial value for the investor. In this sense, more socially responsible firms may have the potential to generate above-average returns for investors. Empirical evidence remains mixed, however, although with a slight positive bias.

While studies on socially responsible behavior and financial performance are likely to continue going forward, scholars have been searching for additional explanations regarding the motivations and incentives for SRI investors. One growing field has examined the role of national business systems, institutional complementarity, and the institutional features of the market influencing the concept and practice of CSR. This approach has emphasized the importance of understanding the institutions and mechanisms underpinning the landscape for socially responsible behavior, particularly the state, firms, other key institutions, and market mechanisms. An examination of these features arguably sheds light on the expectations and outcomes of socially responsible behavior given the goals of the market in question vis-à-vis the institutions that interact with one another. This has practical implications for investors in SRI, as an understanding of the local context for socially responsible behavior would help pinpoint potential opportunities and challenges in the market.

Second, relational theories reflected the integration of social demands in shaping motivations and incentives for SRI. The underlying assumption for this group is that the relational motivation is driven by the need to maintain cooperative relationships among stakeholders and is associated with minimizing social exclusion and building social cohesiveness. In this sense, SRI can serve a reinforcing function in the local conceptualization and practice of socially responsible behavior or an active, gap-filling function where investors can fill gaps in governance in areas that governments are unwilling or inca- 
pable of addressing.

Specific issues explored in this category include firm and investor motivations in environmental, social, and governance issues. Literature suggested that a culture of environmental awareness is most evident. Many firms have embraced environmental responsibilities, as they are often consistent with running more sustainable and cost-efficient operations. Literature on social and governance issues argued that the two areas remain more contested than environmental issues. For social issues, reasons may include the broad definition of "social" and the lack of empirical support linking high levels of social investment to firm financial performance. For governance issues, the contentiousness regarding regulation is especially high for markets of the shareholder-centric, Anglo-American model which emphasizes market mechanisms and minimizes the role of the state. In instances when managers of firms are also the owners, governance issues can prove to be even more contentious. In the latter two cases, investors in SRI may be able to fill in gaps for those markets where there is a need to address social and governance issues, but where the state and/or traditional institutions are not doing so already.

Third, ethical theories understood that the relationship between business and society is embedded with ethical values. As such, motivations for SRI extend from an ethical perspective and have roots in moral or ethical principles stemming from the individual, firm, and national levels. Key themes explored in this section include the role of religious convictions, culture, and legal considerations in driving investment principles and motivations. While this approach may portray SRI investors as agents simply reflecting pervasive ethical standards, investors may also be characterized as exhibiting active, market-creating behavior in that they seek to reward firms for ethicallyacceptable behavior through inclusion in portfolios or punish firms for ethically-questionable behavior through exclusion in the same portfolios. 


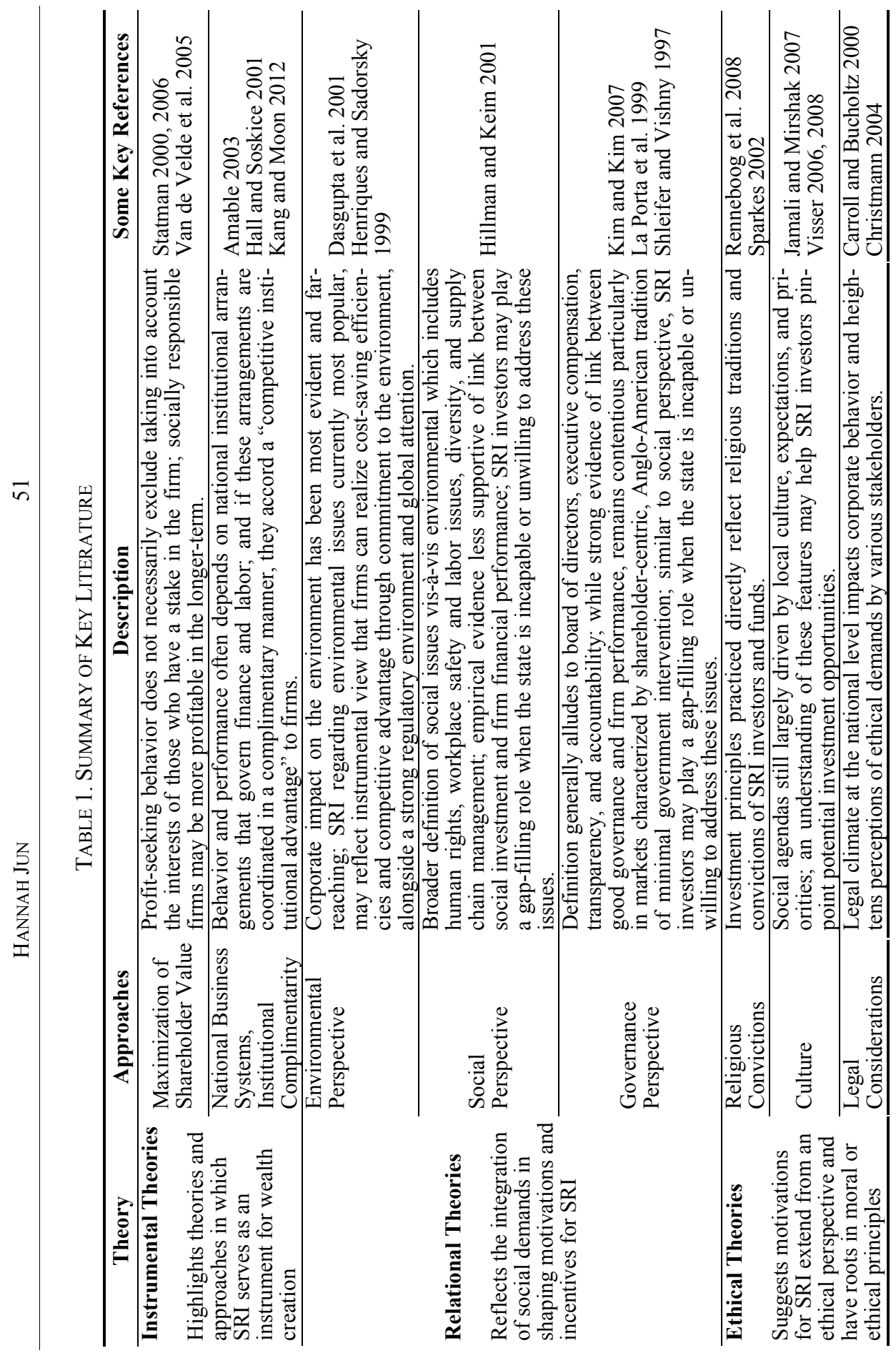


In addition to the three theoretical approaches to understanding motivetions behind the development of SRI, there have been recent attempts to combine the approaches to provide further understanding of the mechanisms and incentive structures underpinning local SRI models. This includes crosscountry empirical studies on investor behavior and preferences by Williams (2007) and qualitative studies on the institutional features driving the model of SRI in Japan by Sakuma and Louche (2008).

\section{REFERENCES}

Aguilera, Ruth, Deborah Rupp, Cynthia Williams, and Jyoti Ganapathi. 2007. Putting the S Back in Corporate Social Responsibility: A Multilevel Theory of Social Change in Organizations. Academy of Management Review 32(3): 836-863.

Amable, Bruno. 2003. The Diversity of Modern Capitalism. Oxford: Oxford University Press.

Barnett, Michael. 2007. Stakeholder Influence Capacity and the Variability of Financial Returns to Corporate Social Responsibility. Academy of $\mathrm{Ma}$ nagement Review 32(3): 794-816.

Barnett, Michael and Robert Salomon. 2006. The Curvilinear Relationship between Social Responsibility and Financial Performance. Strategic Management Journal 27(11): 1101-1122.

Baron, David. 2001. Private Politics, Corporate Social Responsibility, and Integrated Strategy. Journal of Economics and Management Strategy 10(1): 7-45.

Bauer, Rob, Nadja Gunster, and Roger Otten. 2004. Empirical Evidence on Corporate Governance in Europe. Journal of Asset Management 5(2): 91-104.

Bello, Zakri. 2005. Socially Responsible Investing and Portfolio Diversification. The Journal of Financial Research 28(1): 41-57.

Blowfield, Michael, and Jedrzej George Frynas. 2005. Setting New Agendas: Perspectives on Corporate Social Responsibility in the Developing World. International Affairs 81(3): 499-513.

Bowen, Howard. 1953. Social Responsibilities of the Businessman. New York: Harper and Row. 
Brammer, Stephen, Chris Brooks, and Stephen Pavelin. 2006. Corporate Social Performance and Stock Returns: UK Evidence from Disaggregate Measures. Financial Management 35(3): 97-116.

Carroll, Archie. 1991. The Pyramid of Corporate Social Responsibility: Towards the Moral Management of Organizational Stakeholders. Business Horizons: $39-48$.

Carroll, Archie and Ann Bucholtz. 2000. Business and Society: Ethics and Stakeholder Management. Cincinnati: South-Western College Publishing.

Chapple, Wendy and Jeremy Moon. 2005. Corporate Social Responsibility in Asia: A Seven-Country Study of CSR Web Site Reporting. Business and Society 44(4): 415-441.

Chen, Stephen and Petra Bouvain. 2009. Is Corporate Responsibility Converging? A Comparison of Corporate Responsibility Reporting in the USA, UK, Australia, and Germany. Journal of Business Ethics 87(1): 299317.

Christmann, Petra. 2004. Multinational Companies and the Natural Environment: Determinants of Global Environmental Policy Standardization. The Academy of Management Journal 47(5): 747-760.

Cremers, Martijn and Vinay Nair. 2005. Governance Mechanisms and Equity Prices. Journal of Finance 60(6): 2859-2894.

Dasgupta, Susmita, Benoit Laplante, and Nlandu Mamingi. 2001. Pollution and Capital Markets in Developing Countries. Journal of Environmental Economics and Management 42: 310-335.

Derwall, Jeroen, Nadja Gunster, Rob Bauer, and Kees Koedijk. 2005. The Eco-Efficiency Premium Puzzle. Financial Analyst Journal 61(2): 5163.

Donaldson, Thomas, and Lee Preston. 1995. The Stakeholder Theory of the Corporation: Concepts, Evidence, and Implications. The Academy of Management Review 20(1): 65-91.

Eurosif. 2010. European SRI Study 2010.

Gjølberg, Maria. 2010. The Origin of Corporate Social Responsibility: Global Forces or National Legacies?. Socio-Economic Review 7: 605-637.

Gompers, Paul, Joy Ishii, and Andrew Metrick. 2003. Corporate Governance 
and Equity Prices. Quarterly Journal of Economics 118(1): 107-155.

Hall, Peter and David Soskice eds. 2001. Varieties of Capitalism: The Institutional Foundations of Comparative Advantage. Oxford: Oxford University Press.

Henriques, Irene and Perry Sadorsky. 1996. The Determinants of an Environmentally Responsive Firm: An Empirical Approach. Journal of Environmental Economics and Management 30: 381-395.

Hettige, Hemamala, Robert Lucas, and David Wheeler. 1992. The Toxic Intensity of Industrial Production: Global Patterns, Trends, and Trade Policy. The American Economic Review 82(2): 478-481.

Hillman, Amy and Gerald Keim. 2001. Shareholder Value, Stakeholder Management, and Social Issues: What's the Bottom Line? Strategic Management Journal 22: 125-139.

Jackson, Gregory and Androniki Apostolakou. 2010. Corporate Social Responsibility in Western Europe: CSR as an Institutional Mirror or a Substitute?. Journal of Business Ethics 94: 371-394.

Jamali, Dima and Ramez Mirshak. 2007. Corporate Social Responsibility (CSR): Theory and Practice in a Developing Country Context. Journal of Business Ethics 72: 243-262.

Kang, Nahee and Jeremy Moon. 2012. Institutional Complementarity Between Corporate Governance and Corporate Social Responsibility: A Comparative Constitutional Analysis of Three Capitalisms. Socio-Economic Review 10: 85-108.

Kim, E. Han and Woochan Kim. 2007. Corporate Governance in Korea: A Decade After the Financial Crisis. U of Texas Law, Law and Econ Research Paper: 123.

Mackey, Alison, Tyson Mackey, and Jay Barney. 2007. Corporate Social Responsibility and Firm Performance: Investor Preferences and Corporate Strategies. Academy of Management Review 32(3): 817-835.

Margolis, Joshua, Hillary Elfenbein, and James Walsh. 2007. Does It Pay to be Good? A Meta-Analysis and Redirection of Research on the Relationship between Corporate Social and Financial Performance. Ann Arbor 1001: 48109-1234.

Matten, Dirk and Jeremy Moon. 2008. 'Implicit' and 'Explicit' CSR: A Conceptual Framework for a Comparative Understanding of Corporate 
Social Responsibility. Academy of Management Review 33: 404-424.

McWilliams, Abagail and Donald Siegel. 2001. Corporate Social Responsibility: A Theory of the Firm Perspective. Academy of Management Review 26(1): 117-127.

Michelson, Grant, Nick Wailes, Sandra van der Laan, and Geoff Frost. 2004.

Ethical Investment Processes and Outcomes. Journal of Business Ethics 52: $1-10$.

Misani, Nicola. 2010. The Convergence of Corporate Social Responsibility Practices. Management Research Review 33(7): 734-748.

Mitchell, Ronald, Bradley Agle, and Donna Wood. 1997. Toward a Theory of Stakeholder Identification and Salience: Defining the Principle of Who and What Really Counts. The Academy of Management Review 22(4): 853-886.

Moskalev, Sviotoslav, and Seung Chan Park. 2010. South Korean Chaebols and Value-Based Management. Journal of Business Ethics 92: 49-62.

Ogden, Stuart and Robert Watson. 1999. Corporate Performance and Stakeholder Management: Balancing Shareholder and Customer Interests in the U.K. Privatized Water Industry. The Academy of Management Journal 42(5): 526-538.

Renneboog, Luc, Jenke Ter Horst, and Chendi Zhang. 2008. Socially Responsible Investments: Institutional Aspects, Performance, and Investor Behavior. Journal of Banking and Finance 32: 1723-1742.

Sakuma, Kyoko and Celine Louche. 2008. Socially Responsible Investment in Japan: Its Mechanism and Drivers. Journal of Business Ethics 82: 425448.

Schuler, Douglas and Margaret Cording. 2006. A Corporate Social Performance-Corporate Financial Performance Behavioral Model for Consumers. Academy of Management Review 31(3): 540-558.

Shleifer, Andrei and Robert Vishny. 1997. A Survey of Corporate Governance. Journal of Finance 52: 737-783.

Smit, P. J. and G. J. Cronje. 1997. Management principles. Lansdowne: Juta and Co. Ltd.

Social Investment Forum (US SIF). 2003, 2010. Report on Responsible Investing Trends in the US. 
Sparkes, Russell. 2002. Socially Responsible Investment: A Global Revolution. London: John Wiley and Sons.

Statman, Meir. 2000. Socially Responsible Mutual Funds. Financial Analysts Journal 56(3): 30-39.

Statman, Meir. 2006. Socially Responsible Indexes: Composition, Performance, and Tracking Error. The Journal of Portfolio Management 32(3): 100-109.

Van de Velde, Eveline, Wim Vermeir, and Filip Corten. 2005. Corporate Social Responsibility and Financial Performance. Corporate Governance 5(3): 129-138.

Vogel, David. 2005. The Market for Virtue: The Potential and Limits of Corporate Social Responsibility. Washington DC: Brookings Institution Press.

Visser, Wayne. 2006. Revisiting Carroll's CSR Pyramid: An African Perspective. pp. 29-55 in Corporate Citizenship in Developing Countries, edited by E. Pedersen and M. Huniche. The Copenhagen Centre: Copenhagen.

Visser, Wayne. 2008. Corporate Social Responsibility in Developing Countries: 473-479 in The Oxford Handbook of Corporate Social Responsibility, edited by A. Crane, A. McWilliams, D. Matten, J. Moon and D. Siegel. Oxford: Oxford University Press.

Williams, Geoffrey. 2007. Some Determinants of the Socially Responsible Investment Decision: A Cross-Country Study. Journal of Behavioral Finance 8(1): 43-57.

Wood, Donna. 2010. Measuring Corporate Social Performance: A Review. International Journal of Management Reviews 12(1): 50-84.

$\mathrm{Xu}$, Shangkun and Rudai Yang. 2010. Indigenous Characteristics of Chinese Corporate Social Responsibility Conceptual Paradigm. Journal of Business Ethics 93: 321-333.

Yamamura, Kozo, and Wolfgang Streeck eds. 2003. The End of Diversity? Prospects for German and Japanese Capitalism. Ithaca: Cornell University Press. 